\title{
Systematic review and bibliometric analysis of African anesthesia and critical care medicine research part I: hierarchy of evidence and scholarly productivity
}

Ulrick Sidney Kanmounye ${ }^{1,2^{*}}$ (D), Joel Noutakdie Tochie $e^{3,4}$, Aimé Mbonda ${ }^{5,6,7}$, Cynthia Kévine Wafo ${ }^{3}$, Leonid Daya ${ }^{3,7}$, Thompson Hope Atem ${ }^{8}$, Arsène Daniel Nyalundja ${ }^{1,9}$ and Daniel Cheryl Eyaman ${ }^{3}$

\begin{abstract}
Background: Research is an essential component of Anesthesia, and the contributions of researchers and institutions can be appreciated from the analysis of scholarly outputs. Such analyses help identify major contributors and trends in publication. Little is known about the state of Anesthesia and Critical Care Medicine (A.C.C.M.) research in Africa. We aimed to describe African A.C.C.M. research's current landscape by determining its productivity per country and point towards possible ideas for improvement.

Methods: The authors searched PubMed, Embase, Web of Science, and Cumulative Index to Nursing and Allied Health Literature (CINAHL) from inception to May 4, 2020, for articles on or about A.C.C.M. in Africa. Studies were selected based on their titles and abstracts. Rayyan software was later on used for data management in the review selection process. Then, the full-text of eligible articles were screened. Data were extracted, and the number of articles per physician anesthesia providers and provider density were calculated. Kruskal Wallis test and Spearman's correlation were used, and a P-value $<0.05$ was considered statistically significant.

Results: Of the 4690 articles, only 886 (18.9\%) were included in the analysis. The articles were published between 1946 and 2020 in 278 target journals. 55 (6.2\%) articles were published in the South African Journal of Surgery, 51 (5.8\%) in Anesthesia and Analgesia, and 46 (5.2\%) in Anaesthesia. 291 (32.8\%) studies were cross-sectional. 195 (22.0\%) first authors were from Nigeria, 118 (13.3\%) from South Africa, and 88 (9.9\%) from the U.S.A. Malawi (1.67), Togo (1.06), and Sierra Leone (1.00) had the highest number of articles per provider. Whereas Ethiopia (580.00), Nigeria (336.21), and Malawi (333.33) had the highest number of articles per provider density.

Conclusion: We identified the most and least productive African countries in A.C.C.M. research and a low-quality hierarchy of evidence in these publications. Hence, the study's findings may aid in driving the A.C.C.M. research agenda and capacity building in Africa.
\end{abstract}

Keywords: Africa, Anesthesia, Bibliometrics, Global anesthesia, Research

\footnotetext{
* Correspondence: ulricksidney@gmail.com

'Department of Research, Association of Future African Neurosurgeons, Kinshasa, Democratic Republic of Congo

${ }^{2}$ Department of Neurosurgery, Faculty of Medicine, Bel Campus University of Technology, Kinshasa, Democratic Republic of Congo

Full list of author information is available at the end of the article
}

(c) The Author(s). 2020 Open Access This article is licensed under a Creative Commons Attribution 4.0 International License, which permits use, sharing, adaptation, distribution and reproduction in any medium or format, as long as you give appropriate credit to the original author(s) and the source, provide a link to the Creative Commons licence, and indicate if changes were made. The images or other third party material in this article are included in the article's Creative Commons licence, unless indicated otherwise in a credit line to the material. If material is not included in the article's Creative Commons licence and your intended use is not permitted by statutory regulation or exceeds the permitted use, you will need to obtain permission directly from the copyright holder. To view a copy of this licence, visit http://creativecommons.org/licenses/by/4.0/ The Creative Commons Public Domain Dedication waiver (http://creativecommons.org/publicdomain/zero/1.0/) applies to the data made available in this article, unless otherwise stated in a credit line to the data. 


\section{Background}

African anesthesia and critical care medicine (A.C.C.M.) face numerous challenges: delayed patient presentations, lack of equipment, lack of an adequate specialist workforce, poor information management infrastructure, and lack of funding [1-3]. These barriers hamper the development of A.C.C.M. practice, education, and research. Out of the three components of A.C.C.M., research has the greatest potential to change the status quo. First, research can help identify the barriers of universal A.C.C.M. access in Africa [4]. Research has been used, for example, to map the workforce deficit and to identify obstacles to the development of A.C.C.M. services in Africa $[5,6]$. Also, research can help design, monitor, and evaluate context-specific solutions to previously identified problems [4]. This has been the case with the World Health Organization surgical safety checklist, the LifeBox pulse oximeter, and oxygen provision in low-resource settings $[3,7,8]$.

Research can equally improve the career trajectory of individuals and the academic standing of institutions. Their colleagues respect high academic performers, get promoted, and be recruited to more prestigious institutions [9-11]. Similarly, prolific academic institutions attract talented researchers, secure more funding, and gain recognition from the research community and the public [12].

We aimed to describe the landscape of AACM research in Africa, and we hypothesized that the most significant contributions to African A.C.C.M. were from South Africa and Western countries.

\section{Methods}

\section{Search strategy}

A protocol was developed and can be accessed online (https://doi.org/10.13140/RG.2.2.28999.32167). PubMed, Embase, Web of Science, and Cumulative Index to Nursing and Allied Health Literature (CINAHL) were searched from inception to May 4, 2020, using a systematic Boolean search strategy (Additional File 1) developed by an author (U.S.K.). The search was developed without language limits, and it covered articles on or about anesthesia and critical care practice in Africa. Articles in languages none of the authors understood were sent to a professional medical translator on ProZ (http://www.proz.com, ProZ, Syracuse, New York, U.S.A.). After the database search, Google Scholar, ResearchGate, and ORCiD were searched. This hand search was informed using forward and backward citation analyses, i.e., the articles cited by the studies found during the database search and the articles that cited the studies found during the database search.

\section{Screening}

The citations were exported then uploaded on the free online review platform - Rayyan (https://rayyan.qcri.org/,
Doha, Qatar). First, duplicates were excluded, then each article was (title and abstract) screened by at least two reviewers (J.T.N., AM, C.W.S., L.D., TA, A.D.N., and D.C.E.). Next, conflicts were resolved by the authors concerned, and if the two authors could not agree, a third author (U.S.K.) was sought for arbitration.

\section{Data extraction and analysis}

Metadata of all the articles included were extracted - article title, year of publication, author affiliations, study design. The data were stored on Google Forms (Google, Menlo Park, CA, U.S.A.) then imported into SPSS v26 (I.B.M., Armonk, NY, U.S.A.). The publication trends, author contributions, and hierarchy of evidence frequencies were calculated and visualized using Tableau Public (Salesforce, Mountain View, CA, U.S.A.).

The absolute number of published articles is a good measure of academic proficiency and research aptitude; however, it does not factor individual contributions at the level of a nation. Countries with more physician anesthesia providers (P.A.P.s) are expected to have higher research outputs. To account for this, the authors chose to calculate the number of articles per African P.A.P.s. This metric was calculated by dividing the number of first author articles by the number of P.A.P.s from each African country. A major barrier to A.C.C.M. research is the lack of protected research time [13]. The P.A.P. density (P.A.P.s per 100,000 population) was used to account for the clinical workload's effect on research output.

The data on the P.A.P.s (total P.A.P.s and P.A.P.s per 100,000 population) was obtained from a $2015 / 2016$ survey of the World Federation of Societies Anaesthesiologists [14]. Also, correlations were computed between the number of articles and the P.A.P. data. The P.A.P. data of six countries (Botswana, Djibouti, Gambia, Lesotho, Seychelles, and Sudan) was not available, so they were excluded from the analysis. The bivariate analyses (Kruskal Wallis test and Spearman's correlation) were run and considered statistically significant when the $P$-value $<$ 0.05 .

\section{Results}

The search strategy returned 4690 articles: 4688 from databases and 22 from the supplementary hand search. We excluded 705 duplicates and reviewed 3985 nonduplicate articles. After the title and abstract screening, we excluded 2922 more articles because they were irrelevant. Most irrelevant articles returned articles from $\mathrm{Pa}$ pua New Guinea and animal research on guinea pigs in non-African countries (Fig. 1).

\section{Publication trends and target journals}

The final 886 citations were published between 1946 and 2020. The publication trend had three primary 
Inception-May 4, 2020

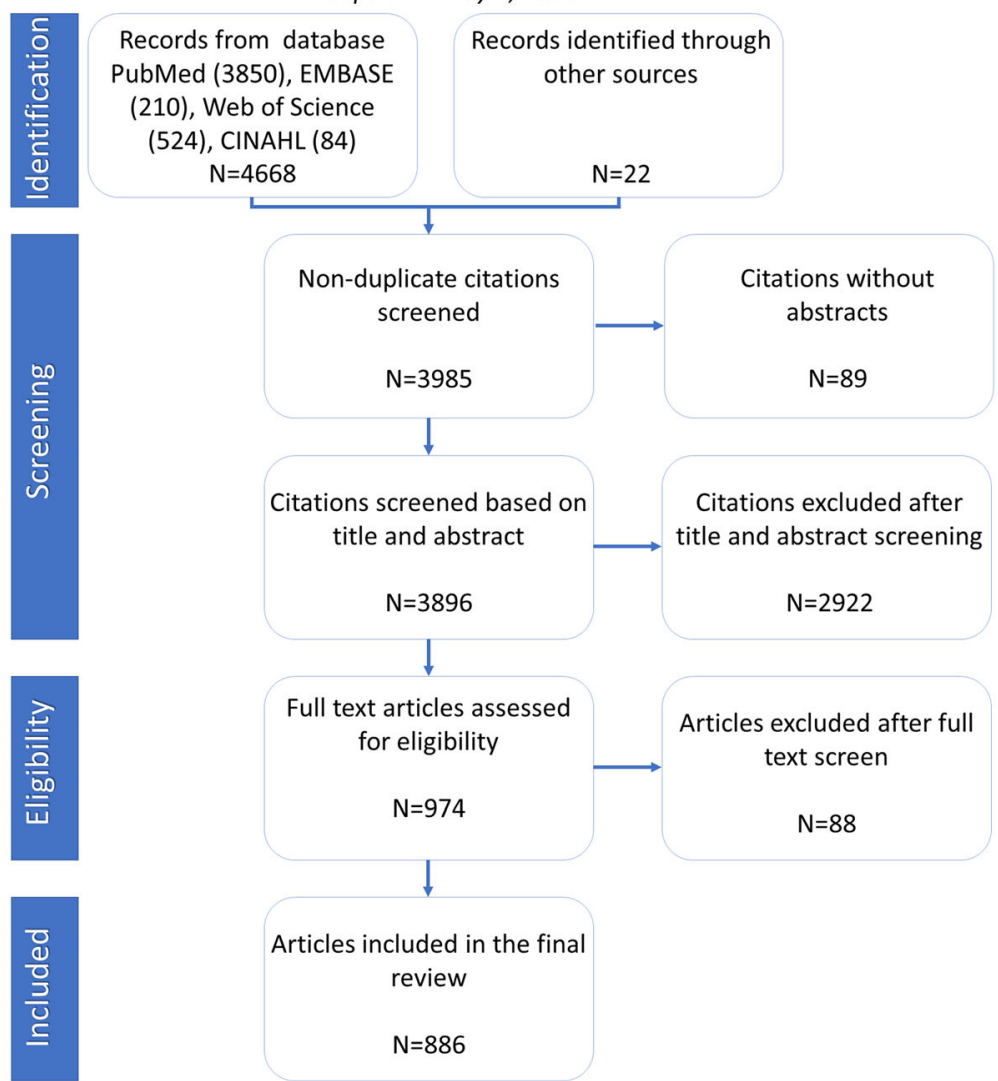

Fig. 1 Flow diagram illustrating the search strategy

cycles with peaks in 1981 (11 articles), 1993 (14 articles), and 2018 (71 articles) $(P=0.48)$ (Fig. 2).

The articles were published in 278 journals. South African Journal of Surgery (55 articles, 6.2\%), Anesthesia and Analgesia (51, 5.8\%), and Anaesthesia (46, 5.2\%) were the top contributors. The top 50 journals are displayed in Table 1.

\section{Hierarchy of evidence}

Most (291, 32.8\%) studies had a cross-sectional design. The next most common study designs were cohort studies $(172,19.4 \%)$ and randomized controlled trials $(76,8.6 \%)$. There were a few animal studies (2, 0.2\%) and published guidelines (1, 0.1\%) (Additional File 2 Table).

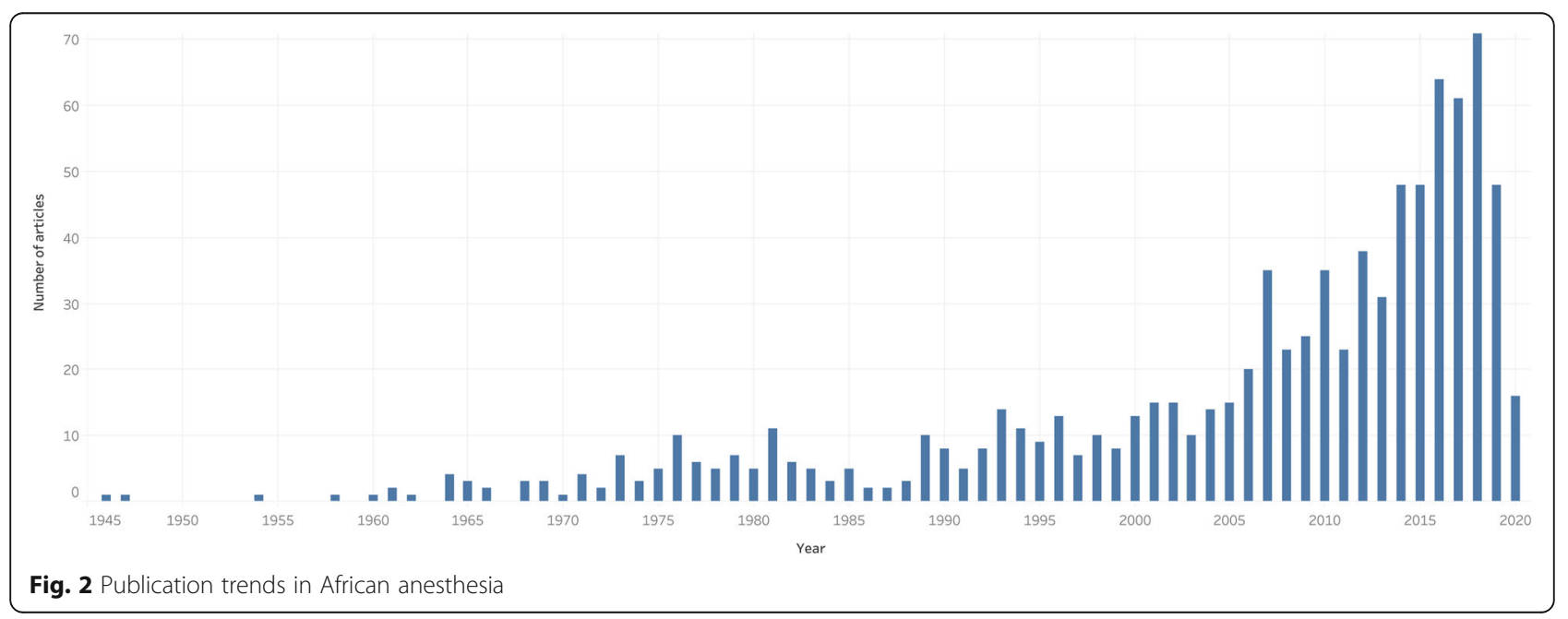


Table 1 Top 50 target journals for African anesthesia research

\section{Journal}

1. South African Journal of Surgery

2. Anesthesia and Analgesia

3. Anaesthesia

4. East African Medical Journal

5. West African Medical Journal

6. Pan African Medical Journal

7. Tropical Doctor

8. Annales Francaises d'Anesthesie et de Réanimation

9. Canadian Journal of Anaesthesia

10. World Journal of Surgery

11. British Journal of Anaesthesia

12. Médecine Tropicale

13. African Journal of Medicine and Medical Sciences

14. International Journal of Gynaecology and Obstetrics

15. The Nigerian Postgraduate Medical Journal

16. African Health Sciences

17. PLoS One

18. La Tunisie Médicale

19. Nigerian Journal of Medicine

20. International Journal of Obstetric Anesthesia

21. Middle East Journal of Anaesthesiology

22. South African Medical Journal

23. Lancet

24. Nigerian Journal of Clinical Practice

25. Dakar Medical

26. Paediatric Anaesthesia

27. African Journal of Paediatric Surgery

28. Anesthesiology

29. B.M.C. Anesthesiology

30. Journal of Obstetrics and Gynaecology

31. Médecine et Santé Tropicales

32. Nigerian Quarterly Journal of Hospital Medicine

33. Anesthesiology Research and Practice

34. B.M.C. Health Services Research

35. B.M.C. Research Notes

36. British Journal of Nursing

37. Journal Français d'Ophtalmologie

38. Journal of Clinical Anesthesia

39. South African Dental Journal

40. Southern African Journal of Anaesthesia and Analgesia

41. The Central African Journal of Medicine

42. Trials

43. African Journal of Reproductive Health

44. Anaesthesia and Intensive Care

\section{Frequency $(N=886)$}

\section{5}

51

46

33

31

26

26

23

21

21

16

16

15

13

13

12

11

10

10

8

8

8

7

7

6

6

5

5

5

5

5

5

4

4

4

4

4

4

4

4

4

4

3

3
Percentage (\%)

6.2

5.8

5.2

3.7

3.5

2.9

2.9

2.6

2.4

2.4

1.8

1.8

1.7

1.5

1.5

1.4

1.2

1.1

1.1

0.9

0.9

0.9

0.8

0.8

0.7

0.7

0.6

0.6

0.6

0.6

0.6

0.6

0.5

0.5

0.5

0.5

0.5

0.5

0.5

0.5

0.5

0.5

0.3

0.3 
Table 1 Top 50 target journals for African anesthesia research (Continued)

\begin{tabular}{lll}
\hline Journal & Frequency $(\boldsymbol{N}=\mathbf{8 8 6})$ & Percentage \\
\hline 45. Annals of The Royal College of Surgeons of England & 3 & 0.3 \\
46. Cahiers d'Anesthésiologie & 3 & 0.3 \\
47. Central African Journal of Medicine & 3 & 0.3 \\
48. Ethiopian Journal of Health Sciences & 3 & 0.3 \\
49. Ethiopian Medical Journal & 3 & 0.3 \\
50. International Anesthesiology Clinics & 3 & 0.3 \\
\hline
\end{tabular}

\section{First author academic output}

The first authors were affiliated with institutions of 62 countries. Most $(36,58.1 \%)$ countries were African, and the median number of first author articles by Africans was $8.5(\mathrm{IQR}=16.25)$. The most productive first authors were affiliated with institutions from Nigeria (195, 22.0\%), South Africa (118, 13.3\%), U.S.A. (88, 9.9\%), UK (65, 7.3\%), and Ethiopia (29, 3.3\%) (Fig. 3).

The median number of articles per African P.A.P.s was $0.13(\mathrm{IQR}=0.38)$, while the median number of articles per African P.A.P. density was 30.65 (IQR = 88.29) articles. Malawi had the highest number of articles per African P.A.P.s (1.67), followed by Togo (1.06), and Sierra Leone (1.00). When taking into account the P.A.P. density, Ethiopia (580.00), Nigeria (336.21), and Malawi (333.33) were the most significant contributors (Table 2). The number of articles was correlated significantly with the number of African P.A.P.s $(R=0.40, P=0.03)$ but not with the African P.A.P. density $(R=0.23, P=0.22)$.

\section{Second and senior author contributions}

There were 245 (27.5\%) single-author articles. Similarly to the first authorship, Nigeria was a major contributor among second authors (133, 15.0\%). South Africa (77, $8.7 \%)$ and the U.S.A. (72, 8.1\%) were the second and third major contributors to second author positions.
While Nigeria remained the major contributor among first authors $(89,10.0 \%)$, South Africa dropped to the third place $(47,5.3 \%)$ behind the U.S.A. 74 (8.4\%) (Fig. 4).

\section{Discussion}

This study is the first comprehensive analysis of A.C.C.M. research in Africa. African A.C.C.M. publication had cycles of increasing amplitude organized around three peaks. Also, we noted an essential increase in the scholarly output over the last 20 years. The articles were published in a variety of journals, and most studies had an observational study design. Moreover, researchers from Nigeria and South Africa contributed the most to the scholarly output.

\section{Academic output}

Malawi, Sierra Leone, and Togo had the highest number of articles per P.A.P. Malawi ranked among the highest contributors in publications, publications per P.A.P.s, and publications per P.A.P. density. This indicates that Malawian P.A.P.s are proficient researchers despite a higher workload. Both Sierra Leone and Togo have median articles per P.A.P. density below the African median. Moreover, Sierra Leone was adversely affected by the Ebola virus disease and benefited from international aid [15]. This aid fostered the creation of

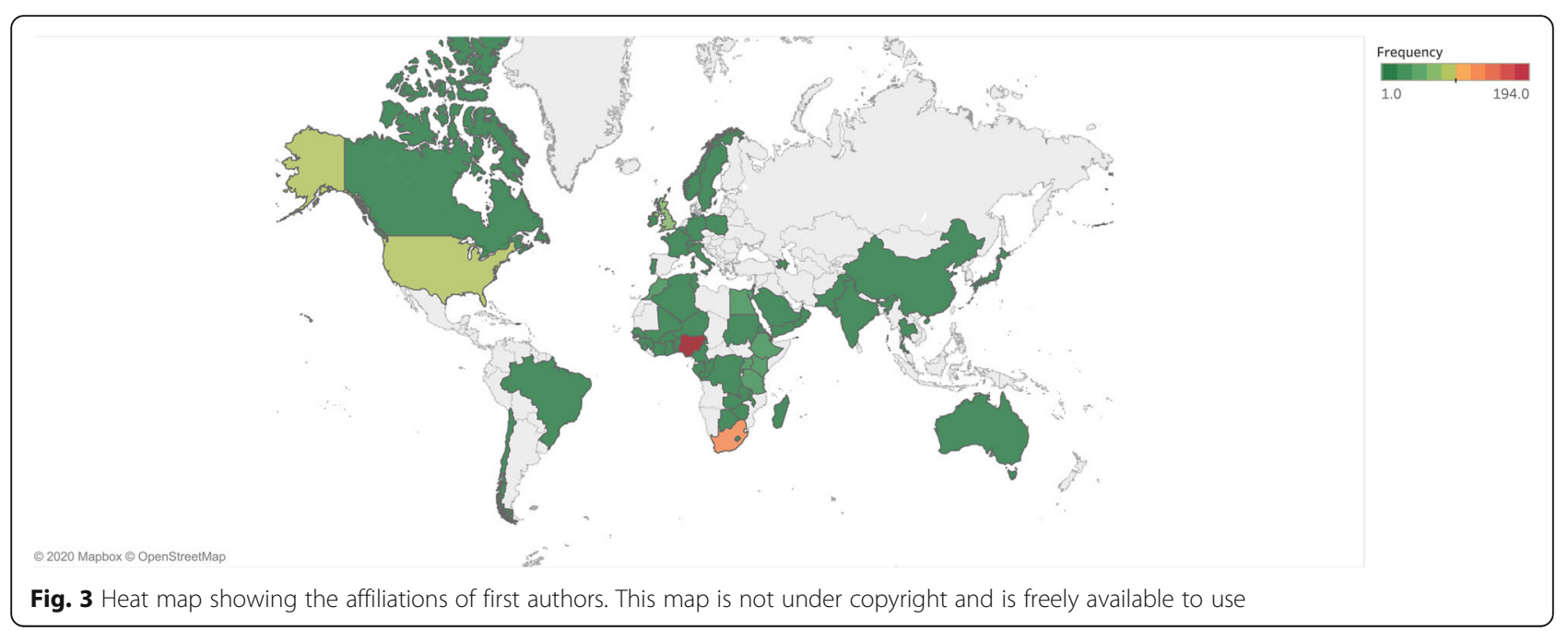


Table 2 Scholarly output per physician anesthesia provider and physician anesthesia provider density

\begin{tabular}{|c|c|c|}
\hline Country & Articles per physician anesthesia provider & Articles per physician anesthesia provider density \\
\hline Algeria & 0.00 & 0.26 \\
\hline Benin & 0.88 & 93.33 \\
\hline Botswana & NA & NA \\
\hline Burkina Faso & 0.04 & 7.14 \\
\hline Cameroon & 0.42 & 100.00 \\
\hline Congo, Rep. & 0.22 & 10.53 \\
\hline Côte d'Ivoire & 0.04 & 9.46 \\
\hline Djibouti & NA & NA \\
\hline D.R.C. & 0.05 & 38.50 \\
\hline Egypt & 0.00 & 3.99 \\
\hline Eritrea & NAN & NAN \\
\hline Ethiopia & 0.57 & 580.00 \\
\hline Gabon & 0.05 & 0.78 \\
\hline Gambia & NA & NA \\
\hline Ghana & 0.13 & 35.00 \\
\hline Guinea & 0.67 & 100.00 \\
\hline Kenya & 0.12 & 56.82 \\
\hline Lesotho & NA & NA \\
\hline Madagascar & 0.13 & 30.43 \\
\hline Malawi & 1.67 & 333.33 \\
\hline Mali & 0.02 & 3.33 \\
\hline Morocco & 0.04 & 14.29 \\
\hline Niger & 0.07 & 14.29 \\
\hline Nigeria & 0.19 & 336.21 \\
\hline Rwanda & 0.33 & 38.24 \\
\hline Senegal & 0.20 & 30.65 \\
\hline Seychelles & NA & NA \\
\hline Sierra Leone & 1.00 & 66.67 \\
\hline South Africa & 0.01 & 7.29 \\
\hline Sudan & NA & NA \\
\hline Tanzania & 0.42 & 233.33 \\
\hline Togo & 1.06 & 78.26 \\
\hline Tunisia & 0.03 & 0.04 \\
\hline Uganda & 0.31 & 122.22 \\
\hline Zambia & 0.13 & 20.41 \\
\hline Zimbabwe & 0.09 & 13.25 \\
\hline
\end{tabular}

NA Data not available, NAN Not a number value

partnerships between local PAPS and foreign P.A.P.s. On the other hand, Togo has trained local P.A.P.s and P.A.P.s from neighboring French-speaking countries, thereby increasing the quantity of Anesthesia research and researchers [16]. Furthermore, Togo and Sierra Leone have relatively small populations (less than 9 million) than other African countries. Hence, increases in the absolute number of articles and P.A.P.s lead to more remarkable changes in the number of articles per P.A.P.s and P.A.P. density.

One-third $(18,33.3 \%)$ of African countries did not have first-author publications. This finding is not surprising because African researchers face numerous barriers to publication.

Barriers faced by African A.C.C.M. researchers include lack of funding, institutional support, inexperience, and 


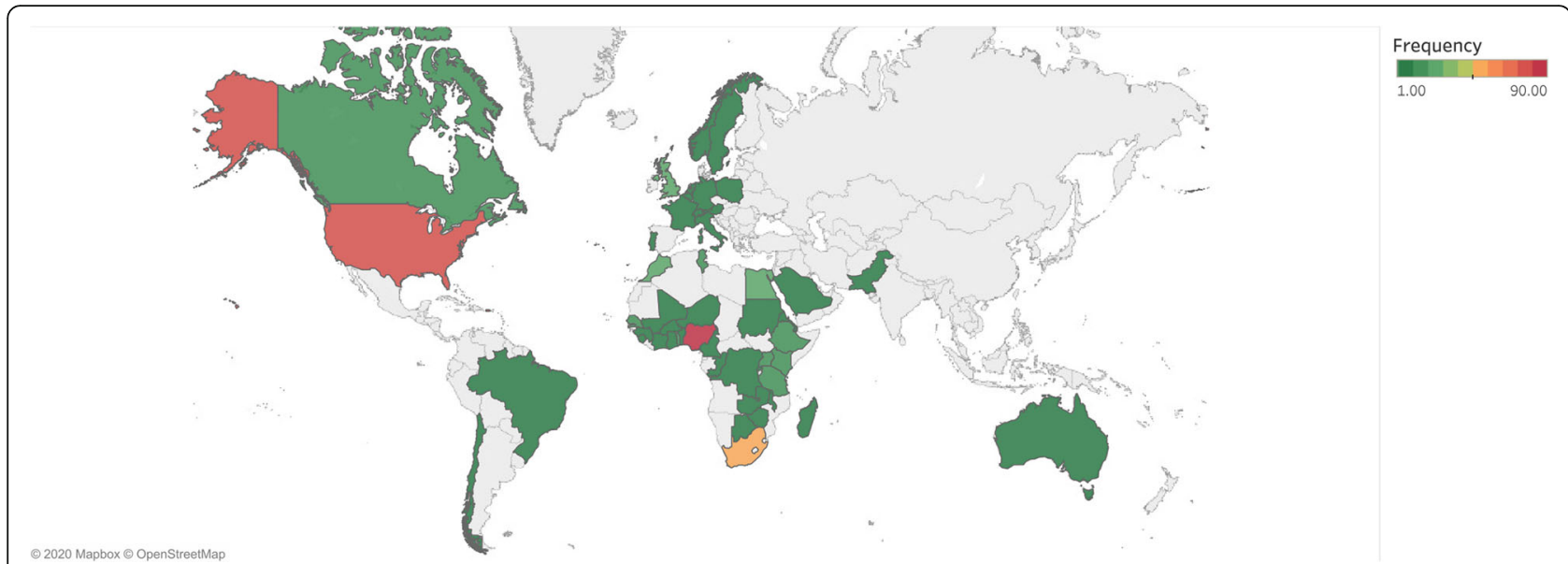

Fig. 4 Heat map showing the affiliations of the last authors. This map is not under copyright and is freely available to use

lack of mentorship [13]. Researchers lack funding to conduct research and to pay for the time spent away from clinical duties. Fortunately, most high impact open access journals offer a sizable discount to researchers from low- and middle-income countries.

African countries, without first author publications, should collaborate with higher-performing countries. The more experienced African researchers can mentor and build capacity among less experienced researchers in neighboring countries. The African Perioperative Research Collaborative is an excellent example of the potential of inter-African A.C.C.M. research collaboratives. The African Perioperative Research Collaborative is a group led by members of the South African Perioperative Research Collaborative that has facilitated A.C.C.M. clinical research among African researchers via technical support, mentorship, and capacity building $[4,17]$.

A sizable proportion $(25,40.3 \%)$ of the first authors were affiliated to non-African institutions, most of them from high-income countries. This might explain why some countries did not have first-author publications. African researchers often assume the role of middle authors when they collaborate with researchers from highincome countries [18]. The lack of first author publications could equally be due to publications in journals that are not indexed in the major databases. Young African researchers often target foreign journals to increase their articles' visibility because most local journals have low impact factors and small readerships [19-22]. However, African researchers face numerous barriers to publish in international journals, especially if they have high impact factors, and some researchers eventually resort to publishing in predatory journals [22]. These predatory journals do not offer transparent and rigorous peer-review and do not meet the indexation criteria in major databases [23]. Further research is needed to understand the causes of the non-representation of the 18 countries.

The most substantial increase in publications occurred during the early 2000s, and they can be explained by increased interest in Global Anesthesia. Global Anesthesia is a field at the crossroads between anesthesia and public health that focuses on access to safe, timely, and affordable anesthesia care in the world. The World Federation of Societies of Anesthesiologists (W.F.S.A.) and prominent specialty journals supported research on access to and safety in anesthesia care. For example, the W.F.S.A. was a founding member and a sponsor of LifeBox and the World Health Organization Safe Surgery checklist, respectively [3, 5, 7]. Moreover, the W.F.S.A., high-income country academic centers, and non-governmental organizations have developed global anesthesia fellowships in South Africa, Ethiopia, Kenya, and Tanzania, contributing significantly to A.C.C.M. research in Africa. This is evidenced by the sizeable contribution of authors affiliated with nonAfrican institutions to African A.C.C.M. research.

\section{Hierarchy of evidence}

There were few systematic reviews and guidelines among the African A.C.C.M. articles. These two forms of information synthesis are among the highest forms of scientific evidence and should inform practice [24]. The integration of evidence-based medicine to A.C.C.M. is common practice today [25]. However, the implementation of international guidelines to A.C.C.M. practice in Africa is faced with numerous challenges that require adaptation [26, 27]. The adaptation of international guidelines is necessary because the guidelines are based on evidence generated in resource-rich milieus, and there is a dearth of evidence-based and context-specific 
African guidelines [28, 29]. African researchers must develop these context-specific African guidelines from high-quality scientific evidence. To increase the quality of the evidence generated, African researchers must hone existing skills and acquire new ones. In systematic reviews, researchers can train using the Cochrane Interactive Learning online resource that offers free access to most African nationals [30].

Also, there were few animal studies among the African A.C.C.M. publications. Although animal studies generate lower-grade scientific evidence, they are essential to the development of A.C.C.M.. For example, animal research played an essential role in developing the Guedel cannula, curarisation, and motor blocks [31]. Africa's rich biodiversity and ethnopharmacology are likely to house the next essential drug in A.C.C.M [32]. This untapped potential could lead to the discovery and production of more affordable drugs for African patients. Unfortunately, African basic science researchers face more barriers than clinical researchers. Researchers are challenged by lack of funding, difficulties obtaining ethical approvals, and inadequate infrastructure [33, 34]. Balogun et al. have proposed the engagement of local and international funding agencies by researchers, the use of invertebrates, and innovative lowcost research methods [35].

\section{Journals}

A significant proportion of the top 50 journals were specialty journals, and only one of the specialty journals was African. Unsustainable financial models can explain the dearth of African specialty journals, lack of editorial expertise, and low submissions quality [36]. All these factors precipitate the failure of young journals. Young specialty journals can curtail the effects of these challenges if they collaborate with more experienced journals. The African Journal Partnership Program provides mentorship and capacity from leading journals of high-income countries to African journals' editorial teams [37].

The African Journal Partnership Program model should be supplemented by inter-African partnerships between more and less experienced journals. The top contributing journal was South African, and the only African specialty journal was equally South African and emphasized the critical role of South African journals in A.C.C.M. research. The prominence of South African journals is an opportunity for other journals to learn from a successful African editorial staff.

A considerable number of articles were published in non-local high impact factor specialty journals. Similar trends have been observed in Europe and South Asia [38, 39]. Publication in a high impact journal does not guarantee visibility or recognition [40]. Citation metrics are better measures of visibility and recognition [41]; however, we did not collect data on citations. Future studies should evaluate the quantitative and qualitative impact of African A.C.C.M. research. Notwithstanding, the publication of African articles in high impact factor journals attests to the quality of research emanating from the continent.

\section{The future of A.C.C.M. research in Africa}

Going forward, African A.C.C.M. research must adopt a "no woman/man left behind" approach. Continental-level professional groups like the Africa Regional Section of the World Federation of Societies of Anesthesiologists should oversee a continental research agenda focused on capacity-building, especially in countries without first author publications. The capacity-building could be organized online and in-person (concomitantly with continental meetings). These training sessions should be opened not only to specialist physicians but equally to nurse anesthetists, residents, and medical students. Nurse anesthetists, residents, and medical students can help decrease the research workload by contributing to data curation, project administration, and writing of original manuscript drafts. In the absence of protected research time, this strategy can "buy" some time for specialist physicians and build capacity among non-physicians.

\section{Limitations}

We acknowledge the following limitations in our study: our definition of African research excluded Africans' research about A.C.C.M. in other continents. Next, we considered studies to be equal irrespective of their citation metrics or study design. Therefore, we did not factor the impact of the studies into the contributions. Hence, a letter to the editor with lower citation metrics was considered equal to a systematic review with higher citation metrics. Finally, we limited our analysis to prominent author positions. As such, we failed to capture a detailed picture of the contributors to African A.C.C.M. research. In addition, our search strategy could have been more explicit. We initially opted for a more comprehensive search strategy, but the results returned many irrelevant results. Given our limited resources, we opted for a less broad search. Despite these limitations, we believe our study adds value to existing research.

\section{Conclusion}

This study analyzed the publication trends, study designs, target journals, and contributions to A.C.C.M. research in Africa. There has been an increase in article publication over the past two decades, and the greatest contributors are Nigeria and Malawi. This analysis helped to identify less productive countries, subspecialties, and study designs. As such, our findings can be used to set the A.C.C.M. research agenda in Africa. 


\section{Supplementary information}

Supplementary information accompanies this paper at https://doi.org/10. 1186/s12871-020-01167-8.

Additional file 1. Search Strategy.

Additional file 2. African anesthesia and critical care medicine research output by study design.

\section{Abbreviations}

A.C.C.M: Anesthesia and critical care medicine; P.A.P.s: Physician anesthesia providers

\section{Acknowledgments}

We wish to thank Daniel S. Nteranya for his help during the initial stages of the investigation.

\section{Authors' contributions}

U.S.K. conceptualized the study, investigated, curated, analyzed, and visualized the data, wrote the original draft of the manuscript, and administered the project. J.N.T., A.M., C.K.W., L.D., T.H.A., A.D.N., and D.C.E. investigated, validated, and wrote the original manuscript draft. All authors have read and approved the manuscript

\section{Funding}

Not applicable.

\section{Availability of data and materials}

The datasets used and/or analysed during the current study are available from the corresponding author on reasonable request.

\section{Ethics approval and consent to participate}

Not applicable.

\section{Consent for publication}

Not applicable.

\section{Competing interests}

The authors declare that they have no competing interests.

\section{Author details}

${ }^{1}$ Department of Research, Association of Future African Neurosurgeons, Kinshasa, Democratic Republic of Congo. ${ }^{2}$ Department of Neurosurgery, Faculty of Medicine, Bel Campus University of Technology, Kinshasa, Democratic Republic of Congo. ${ }^{3}$ Department of Anesthesiology and Critical Care Medicine, Faculty of Medicine and Biomedical Sciences, University of Yaounde I, Yaounde, Cameroon. ${ }^{4}$ Human Research Education and Networking, Yaounde, Cameroon. ${ }^{5}$ Faculty of Medicine and Biomedical Sciences, University of Yaounde I, Yaounde, Cameroon. ${ }^{6}$ Surgery Unit, District Hospital of Batouri, Batouri, Cameroon. ${ }^{7}$ Department of Research, International Student Surgical Network, Yaounde, Cameroon. ${ }^{8}$ Department of Internal Medicine, Faculty of Medicine, Bel Campus University of Technology, Kinshasa, Democratic Republic of Congo. ${ }^{9}$ Faculty of Medicine, Catholic University of Bukavu, Bukavu, Democratic Republic of Congo.

\section{Received: 9 July 2020 Accepted: 20 September 2020}

Published online: 28 September 2020

\section{References}

1. Epiu I, Tindimwebwa JVB, Mijumbi C, Chokwe TM, Lugazia E, Ndarugirire F, et al. Challenges of anesthesia in low- and middle-income countries: A cross-sectional survey of access to safe obstetric anesthesia in East Africa. Anesth Analg. 2017;124:290-9.

2. Epiu I, Wabule A, Kambugu A, Mayanja-Kizza H, Tindimwebwa JVB, Dubowitz G. Key bottlenecks to the provision of safe obstetric anaesthesia in low- income countries; a cross-sectional survey of 64 hospitals in Uganda. BMC Pregnancy Childbirth. 2017;17:387

3. Epiu I, Tindimwebwa JVB, Mijumbi C, Ndarugirire F, Twagirumugabe T, Lugazia ER, et al. Working towards safer surgery in Africa; a survey of utilization of the WHO safe surgical checklist at the main referral hospitals in East Africa. BMC Anesthesiol. 2016;16:60.
4. Biccard BM. Priorities for peri-operative research in Africa. Anaesthesia. 2020; 75:e28-33.

5. Dubowitz G, Detlefs S, McQueen KAK. Global anesthesia workforce crisis: a preliminary survey revealing shortages contributing to undesirable outcomes and unsafe practices. World J Surg. 2010;34:438-44.

6. Ho M, Livingston P, Bould MD, Nyandwi JD, Nizeyimana F, Uwineza JB, et al. Barriers and facilitators to implementing a regional anesthesia service in a low-income country: a qualitative study. Pan Afr Med J. 2019;32. https://doi. org/10.11604/pamj.2019.32.152.17246.

7. Dubowitz G, Breyer K, Lipnick M, Sall JW, Feiner J, Ikeda K, et al. Accuracy of the Lifebox pulse oximeter during hypoxia in healthy volunteers. Anaesthesia. 2013;68:1220-3.

8. Walker IA, Bashford T, Fitzgerald JE, Wilson $\mathrm{H}$. Improving anesthesia safety in low-income regions of the world. Curr Anesthesiol Rep. 2014;4:90-9.

9. Swaminathan M, Glas KE, Heller L, Augoustides JGT, Culp WC, Sniecinski RM. Mission possible: successful careers in adult cardiothoracic anesthesiologywhat I wish I had known in the first 5 years after fellowship. J Cardiothorac Vasc Anesth. 2017;31:321-8.

10. Culley DJ, Fahy BG, Xie Z, Lekowski R, Buetler S, Liu X, et al. Academic productivity of directors of ACGME-accredited residency programs in surgery and anesthesiology. Anesth Analg. 2014;118:200-5.

11. Ahmad S, De Oliveira GS, McCarthy RJ. Status of anesthesiology resident research education in the United States: structured education programs increase resident research productivity. Anesth Analg. 2013;116:205-10.

12. Wood M. Maintaining and fostering the future success of academic anesthesia: recruiting and training the next generation of academic anesthesiologists. Anesth Analg. 2013;116:1-3.

13. Elobu AE, Kintu A, Galukande M, Kaggwa S, Mijjumbi C, Tindimwebwa J, et al. Research in surgery and anesthesia: challenges for post-graduate trainees in Uganda. Educ Health Abingdon Engl. 2015;28:11-5.

14. Kempthorne P, Morriss WW, Mellin-Olsen J, Gore-Booth J. The W.F.S.A. Global anesthesia workforce survey. Anesth Analg. 2017;125:981-90.

15. Bolkan HA, van Duinen A, Samai M, Bash-Taqi DA, Gassama I, Waalewijn B, et al. Admissions and surgery as indicators of hospital functions in Sierra Leone during the west-African Ebola outbreak. B.M.C. Health Serv Res. 2018;18:1-9.

16. Maman A, Zoumenou E, Zéminkandé J, Kaboré F, Bula Bula I, Tagirumugabe $T$, et al. Anaesthesia training: where and how it is conducted in Frenchspeaking sub-Saharan Africa? Update Ahesthesia. 2008;24:42-4.

17. Biccard BM, Madiba TE, Kluyts H-L, Munlemvo DM, Madzimbamuto FD, Basenero A, et al. Perioperative patient outcomes in the African surgical outcomes study: a 7-day prospective observational cohort study. Lancet. 2018:391:1589-98.

18. Hedt-Gauthier BL, Jeufack HM, Neufeld NH, Alem A, Sauer S, Odhiambo J, et al. Stuck in the middle: a systematic review of authorship in collaborative health research in Africa, 2014-2016. BMJ Glob Health. 2019;4:e001853.

19. Kokwaro G, Kariuki S. Medical research in Africa: problems and some solutions. Malawi Med J J Med Assoc Malawi. 2001:13:40.

20. Rusakaniko S, Makanga M, Ota MO, Bockarie M, Banda G, Okeibunor J, et al. Strengthening national health research systems in the WHO African region progress towards universal health coverage. Glob Health. 2019;15:50.

21. Dhalla KA, Guirguis M. Barriers and incentives for conducting research amongst the ophthalmologists in sub-Sahara Africa. PLoS One. 2018;13:e0197945.

22. Tarkang EE, Bain LE. The bane of publishing a research article in international journals by African researchers, the peer-review process and the contentious issue of predatory journals: a commentary. Pan Afr Med J. 2019;32. https://doi.org/10.11604/pamj.2019.32.119.18351.

23. Huh S. How to add a journal to the international databases, science citation index expanded and medline. Arch Plast Surg. 2016;43:487-90.

24. Schulman SR, Schardt C, Erb TO. Evidence-based medicine in anesthesiology. Curr Opin Anaesthesiol. 2002;15:661-8.

25. Myles PS, Bain DL, Johnson F, McMahon R. Is anaesthesia evidence-based? A survey of anaesthetic practice. Br J Anaesth. 1999:82:591-5.

26. Chica $\mathrm{HO}$, Okello E. Evidence-based medicine practice in Africa: is it feasible? Trop Dr. 2009:39:61-2

27. Mellins CA, Nestadt D, Bhana A, Petersen I, Abrams EJ, Alicea S, et al. Adapting evidence-based interventions to meet the needs of adolescents growing up with H.I.V. in South Africa: the VUKA case example. Glob Soc Welf Res Policy Pract. 2014;1:97-110.

28. Motani P, Van de Walle A, Aryeetey R, Verstraeten R. Lessons learned from evidence-informed decision-making in Nutrition \& Health (EVIDENT) in Africa: a project evaluation. Health Res Policy Syst. 2019;17:12. 
29. Aryeetey R, Holdsworth M, Taljaard C, Hounkpatin WA, Colecraft E, Lachat C, et al. Evidence-informed decision making for nutrition: African experiences and way forward. Proc Nutr Soc. 2017;76:589-96.

30. Cochrane Interactive Learning. Cochrane Training. Cochrane Training. 2020. https://training.cochrane.org/. Accessed July 82020.

31. Goyal R. Animal testing in the history of anesthesia: now and then, some stories, some facts. J Anaesthesiol Clin Pharmacol. 2015;31:149-51.

32. Malterud KE. Ethnopharmacology, chemistry and biological properties of four Malian medicinal plants. Plants. 2017;6. https://doi.org/10.3390/ plants6010011.

33. Nyika A. Animal research ethics in Africa: an overview. Acta Trop. 2009; 112(Suppl 1):S48-52.

34. Grants awarded to support small animal research in Africa. Vet Rec. 2016; 178:432. https://veterinaryrecord.bmj.com/content/178/18/432.2.

35. Balogun WG, Cobham AE, Amin A, Seeni A. Advancing neuroscience research in Africa: invertebrate species to the rescue. Neuroscience. 2018; 374:323-5.

36. Goehl TJ, Flanagin A. Enhancing the quality and visibility of African medical and health journals. Environ Health Perspect. 2008;116:A514-5.

37. Bickton FM, Manda-Taylor L, Hamoonga R, Mwenda AS. Challenges facing sub-Saharan African health science journals and benefits of international collaborations and partnerships. Sci Ed. 2019:42:116-9.

38. Figueredo E, Muñoz BF. Evaluation and evolution of the scientific production by Spanish anesthesiology departments. Rev Esp Anestesiol Reanim. 2002;49:306-13.

39. Chen S-Y, Wei L-F, Ho C-M. Trend of academic publication activity in anesthesiology: A 2-decade bibliographic perspective. Asian J Anesthesiol. 2017;55:3-8.

40. Brink PA. Article visibility: journal impact factor and availability of full text in PubMed central and open access. Cardiovasc J Afr. 2013;24:295-6.

41. Baltussen A, Kindler CH. Citation classics in anesthetic journals. Anesth Analg. 2004;98:443-51 table of contents.

\section{Publisher's Note}

Springer Nature remains neutral with regard to jurisdictional claims in published maps and institutional affiliations.

Ready to submit your research? Choose BMC and benefit from:

- fast, convenient online submission

- thorough peer review by experienced researchers in your field

- rapid publication on acceptance

- support for research data, including large and complex data types

- gold Open Access which fosters wider collaboration and increased citations

- maximum visibility for your research: over $100 \mathrm{M}$ website views per year

At $\mathrm{BMC}$, research is always in progress.

Learn more biomedcentral.com/submissions 